\title{
MEDICINAL PLANTS USED BY TRADITIONAL HEALERS FOR SKIN DISEASES AT PIRGANJ IN BANGLADESH
}

\section{HANIF TAHSIN}

Department of Unani Medicine, Hamdard University, Bangladesh

\begin{abstract}
Background: Skin diseases are common and often have an impact on an individual's health-related quality of life. Skin diseases have been of major concern recently due to their association ruler area. It is known that the lay people in this area depend on medicinal plants for their primary health care. Find out scientific validation of those plants used by traditional healer. The investigated which medicinal plants use in skin diseases.
\end{abstract}

Aims: The objective for this study was to perform on easement of skin disease prevalence in our country and assess to the associated impact of any skin disease. The study area was visited several times the study period.

Methods: The information collected from traditional healer they use treating skin diseases. After obtaining their consent, information regarding their knowledge of medicinal plants is recorded with the help of questionnaire-based interview and the data collection by traditional healer. The Survey purposely selected and participant traditional healers. This study has identified medicinal plants used for skin disease treatment by traditional healer in Pirganj, Rangpur, Bangladesh. Generally fresh part of the plant used to preparation of medicine. When fresh plant part are not available dried parts also used in primary health care of people. During the survey it was that there must need to protect this knowledge forever. This might not reflect the actual scenario of the whole country.

Result: This medicinal plants use: Azadirachta indica, Curcuma longa, Aloe Vera/Aloe inlica, Allium sativum, Allium cepa, Pterocarpus santalinus, Solanum lycopersicum, Curcuma aromatica Salisb, Vitex negundo, Cassia angustifolia, Terminalia Chebula, Celosta argentea, Mentha spicata/Arvensis, Solanum ingrum, Rosa damascena, Androgrphis paniculata, Lawsonia inermis, Nigella sativa, Nymphaea nouchali, Mimosa pudica, Pericaria hydro piper, Terminalia bellarica, Ficus carica, Citrus, Centella asiatica. Common treatment of skin diseases in traditional healers include rashes, eczema, leprosy and skin disease, fever, purification of blood, leaves is anti-septic, boils, ringworm, scabies, ulcers, eczema, antiviral, anti-fungal, ringworm, itching, wound, scabies, swelling, viral infections, bacterial infections, fungal infections, parasitic infections, pigmentation disorder.

Conclusion: This study has identified 25 medicinal plants used for skin disease Treatment by Traditional Healer in Pirganj Upazila, Rangpur.

KEYWORDS: Skin Diseases; Anti-Septic Effect; Traditional Healer; Treatment

Received: Feb 16, 2021; Accepted: Mar 06, 2021; Published: May 03, 2021; Paper Id.: IJBRDJUN20215

\section{ABBREVIATIONS}

1. WHO- World Health Organization

2. UV-Use value

3. UNO- Upazila Nirbahi Officer 
4. B.C-Before Christ

5. TM- Traditional Medicine

6. EM-Ethno-medical

7. CM-Centimeter

8. ABTS-2'-azinobis-(3-ethylbenzothiazoline-6-sulfonic acid)

9. AChE-Acetylcholinesterase

10. DPPH-2-diphenyl-1-picrylhydrazyl

11. BChE-Butyrylcholinesterase

12. Na-Sodium

13. K-Potassium

14. Ca-Calcium

15. Cu-Copper

16. Fe-Iron

17. Mg-Magnesium

18. Zn-Zinc

19. P-Phosphorus

20. LDO-Limit of Detection

\section{INTRODUCTION}

\subsection{Background}

Skin is the largest organ in our body. It protects skin from bacteria and viruses and regulates our body temperature. Conditions that irritate, clog or inflame the skin can cause symptoms such as redness, swelling, burning, and itching, allergies, irritants, your genetic makeup and certain diseases and immune system problems can cause dermatitis, hives, and other skin conditions.

WHO (World Health organization) estimate over $80 \%$ the people in depended countries depend on traditional medicines for their primary health needs ${ }^{[1]}$. Bangladesh is one of the largest producers of medicinal herbs and is rightly called the botanical garden of the world as it is sitting on a gold mine of well-recorded and traditionally well practiced knowledge of herbal medicine. About 17,000 species of Bangladeshi flora about 7500 species of higher plants are reported to possess medicinal value and in other countries it is projected about $7 \%$ and $13 \%{ }^{[2]}$. There are estimated to be around 25,000 effective plant-based formulations, used in folk medicine and known to rural communities in Bangladesh ${ }^{[3]}$. Since medicinal plants are nontoxic and easily affordable they play a vital role not only for pharmacological research and drug development, but also when plant constituents are used directly as therapeutic agents and as starting materials for the synthesis of drug ${ }^{[4]}$. 
Traditions in various countries of the world such as Bangladesh, India, China, Egypt, Greek, Roman and Syria bring new insight into plant usage and become established as a rewarding tool for ethno-pharmacological research. In Bangladesh a number of studies have been in use, under indigenous systems of medicine like Unani, Ayurvedic ${ }^{[5-8]}$. The skin diseases are one such common disorder, effecting people worldwide, particularly in rural areas of developing countries due to poor sanitation and inattentiveness to dietary food supplements ${ }^{[9]}$. It is found in all ages with an incidence of $34 \%$ of all occupational diseases ${ }^{[10]}$.

Common skin diseases include rashes, eczema, leucoderma, ringworm, itching, wound, scabies, swelling, viral infections, bacterial infections, fungal infections, parasitic infections, pigmentation disorder, cancer and many others without distinct symptoms and are caused by a variety of micro-organisms and uncomfortable environment ${ }^{[11]}$. Microorganisms responsible for skin infections can be bacterial, fungal, parasitic or viral in nature. Many allopathic drugs prescribed for skin diseases have adverse effects. Consequently, there is an increased interest and confidence in alternative therapies, like phytomedicine, in the treatment of skin ailments ${ }^{[12]}$. Currently, many natural products from plants have been used by various cultures all over the world to treat skin diseases or their symptoms caused by micro-organisms [13]. Although efforts are on to document ethno-botanical information for the treatment (medicinal plants) of skin ailments in different parts of Bangladesh. Therefore, the current investigation aims to, identify, collect and document the medicinal plants traditionally used for the treatment of skin disorders in Bangladesh.

World Health Organization reported that thou traditional medical practitioners treat about $85 \%$ of patients in Bangladesh [14]. This shows the significant valuable relation between local tribal people with use medicinal plants. The writings indicate that therapeutic use of plant is being practiced since 5000-4000 B.C. and Chinese used first the natural herbal preparations as medicines. In Greek, India, Bangladesh, China, Pakistan however, earliest references of use of plants as medicine appear in Rig-Veda which is said to be written between 3500-1600 B.C. Later the properties and therapeutic uses of medicinal plants were studied in detail and recorded empirically by the ancient physician in Unani, Ayurvedic which is a basic foundation of ancient medical science in Bangladesh ${ }^{[15]}$.

Therefore an attempt has been made to explore the traditional healthcare system of the Medicine. Consequently, this study was designed with the aim to document the reliable information on indigenous ethno-medical knowledge of traditional healers and to provide baseline information for further chemical and pharmacological investigation for the advancement and improvement in animal drugs system. Bangladesh was a well-developed Unani, Ayurvedic system of medicine before the Allopathic Medicine became widely available. Even now large segments of the population seek Unani, Ayurvedic treatment particularly in rural areas. Some of the plants used by the Unani and Ayurvedic Medicine for skin disease.

Skin diseases have been of major concern recently due to their association ruler area. It is known that the lay people in this area depend on medicinal plants for their primary health care. However no survey has been done in Pirganj, Rangpur. Many skin diseases in developing countries are associated with socioeconomic factors. It is generally agreed that a public health approach to dermatology in this setting is particularly appropriate; but, there has been little epidemiologic research done to examine which particular socioeconomic factors are important determinants of the prevalence of skin disease. This is especially in Pirganj, Rangpur, Bangladesh. 
Chart 1: List of Medicinal Plants Found by Traditional Healer at Pirganj, Rangpur, Bangladesh

\begin{tabular}{|l|l|c|}
\hline \multicolumn{1}{|c|}{ English Name } & \multicolumn{1}{c|}{ Scientific name } & Page no \\
\hline Margo's & Azadirachta indica & 12 \\
\hline Turmeric & Curcuma longa & 13 \\
\hline Indian aloe & Aloe Vera/Aloe inlica & 14 \\
\hline Garlic & Allium sativum & 15 \\
\hline Onion & Allium cepa & 16 \\
\hline Red sandel & Pterocarpus santalinus & 17 \\
\hline Tomato & Solanum lycopersicum & 18 \\
\hline Wild turmeric & Curcuma aromatica Salisb & 19 \\
\hline Chaste tree & Vitex negundo & 20 \\
\hline Chaste tree & Cassia angustifolia & 21 \\
\hline Chebulic myrobalan & Terminalia Chebula & 22 \\
\hline Silver cocks comb & Celosta argentea & 23 \\
\hline Spearmint & Mentha spicata/Arvensis & 24 \\
\hline Black night shade & Solanum ingrum & 25 \\
\hline Rose & Rosa damascena & $26-27$ \\
\hline Chiretta & Androgrphis paniculata & 28 \\
\hline Henna & Lawsonia inermis & 29 \\
\hline Black Caraway & Nigella sativa & 30 \\
\hline Water lily & Nymphaea nouchali & 31 \\
\hline Mimosa & Mimosa pudica & 32 \\
\hline Water paper & Pericaria hydro piper & 33 \\
\hline Belerica myrobalan & Terminalia bellarica & 34 \\
\hline Common fig & Ficus carica & 35 \\
\hline Lemon & Citrus limon & 37 \\
\hline Indian pennywort & Centella asiatica & \\
\hline & & 38 \\
\hline
\end{tabular}

\subsection{Description of Medicinal Plants use by Traditional Healer at Pirganj, Rangpur, Bangladesh}

\section{Margo's}

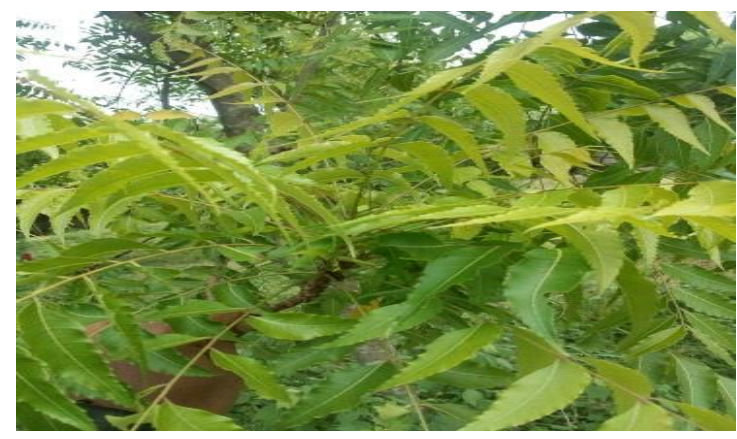

Figure 1: Azadirachta indica

English name: Nim, Margo's

Scientific name: Azadirachta indica

Unani Name: Neem

Family: Meliaceae

Uses: Leprosy, fever, purification of blood, leaves is anti-septic, boils, ringworm, scabies, ulcers and eczema, astringent and antihelmintic, antiviral and anti-fungal. 


\section{Chemical Composition:}

Leaves: Nimbidin, Nimbin, Nimbinin, Nimbidol, Bakayanin ascorbic acid and amino acids.

Fruits: Triterpenoids, Salanin, Azadirachtin.

Barks: Tainnin, Margosin, Azadarin.

\section{Turmeric}

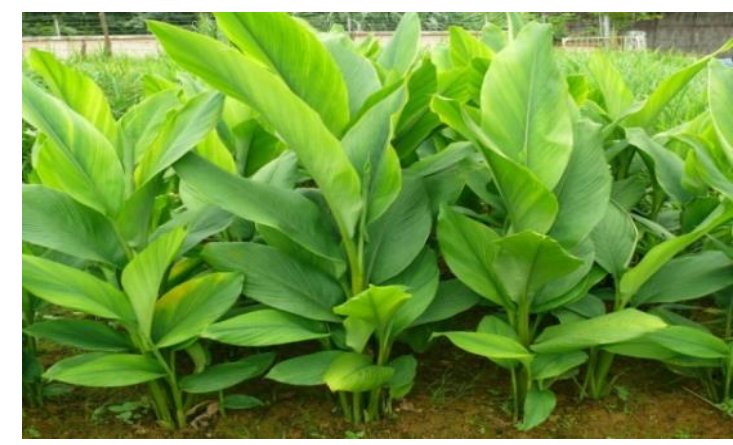

Figure 2: Curcuma longa

English name: Termeric

Scientific name: Curcuma longa

Unani Name: Holdi

Family: Zingiberaceae

\section{Chemical Composition}

- Rhizome contains not more than $4.0 \%$ of volatile oil.

- Not more than $3.0 \%$ of curecuminoids and also cur cumin.

- $\quad$ Turemerone and sesquiterpenes.

- Hydroxyinnamic and hydroxybenzoic acids and oleoresin.

Uses: Anti-inflammatory, skin diseases, stomachic, carminative.

\section{Indian aloe}

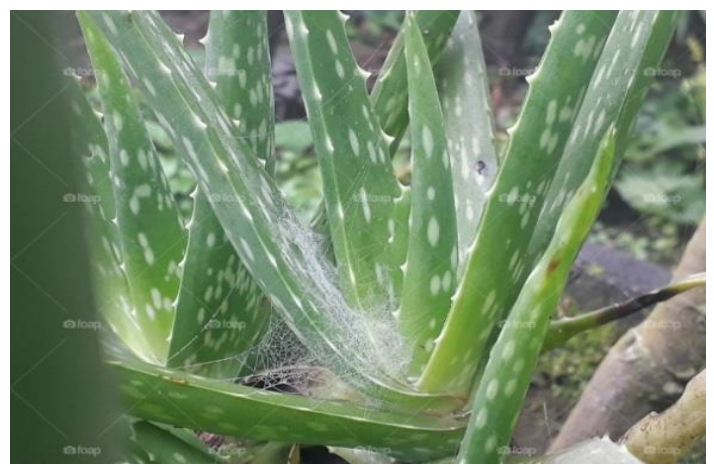

Figure 3: Aloe inlica 
English name: Indian aloe, Barbados aloe

Scientific name: Aloe inlica

Unani Name: Gicoare

Family: Liliaceae

\section{Chemical Composition}

- Aloe Vera contains 75 potentially active constituents: vitamins, enzymes, minerals, sugars, lignin, saponins, aloin, acemannan, salicylic acids and amino acids.

- Vitamins: It contains vitamins A (beta-carotene), $\mathrm{C}$ and $\mathrm{E}$, which are antioxidants. It also contains vitamin B12, folic acid and choline.

Uses: Its use for Skin and Urine disorder, Liver and Spleen enlargement, chronic ulcers, Stomachic, Purgative, Antihelmintic, Aphrodisiac and Tonic, Sexual ejaculation.

\section{Garlic}

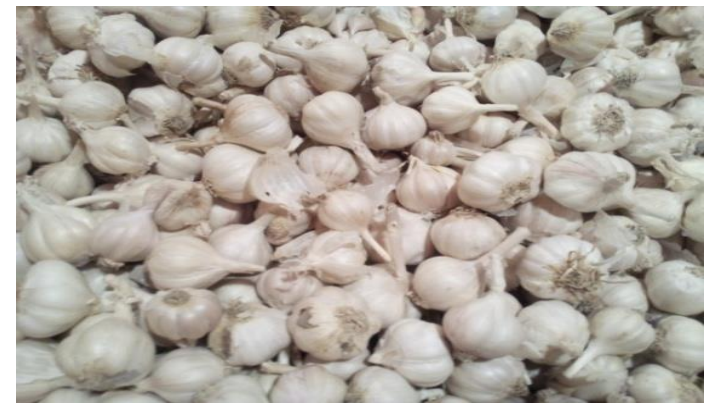

Figure 4: Allium sativum

English name: Garlic

Scientific name: Allium sativum

Unani Name: Lohsun

Family: Liliaceae

\section{Chemical Composition}

Fresh or crushed garlic yields the sulfur-containing compounds alliin, ajoene, diallylpolysulfides, vinyldithiins, Sallylcysteine, and enzymes, saponins, flavonoids, and Maillard reaction products, which are not sulfur-containing compounds.

These are typical phytochemicals found in garlic: garlic contains flavonoids and Sulphur-containing compounds: diallylsulphate, alliin, ajoene, allicin.

Anti-bacterial and anti-virus: Infections, strong oxidant, strong antibiotic property.

Anti-inflammatory: Many scientific studies have shown fresh garlic and garlic powder have anti-inflammatory action.

\section{Onion}




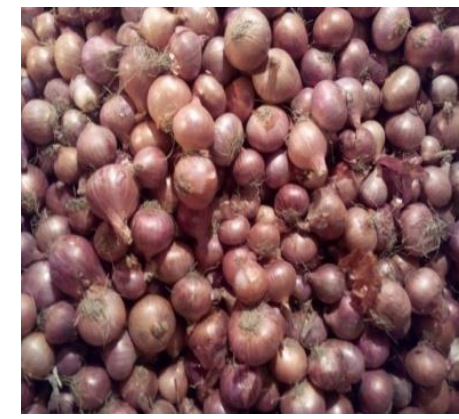

Figure 5: Allium sativum

English name: Onion

Scientific name: Allium cepa

Unani Name: Bosol

Family: Liliaceae

\section{Chemical Composition}

Flavonoid, phenol content, scavenge 2, 2-diphenyl-1-picrylhydrazyl (DPPH), antioxidant, carbohydrate, proteins, flavonols, bioflavonoid.

Uses

Scar removal, rashes, skin diseases, high cholesterol, diabetes, joint disorder, digestive, gall bladder disorder, angina pectoris, high blood pressure, atherosclerosis, asthma, hair loss, bronchitis, cough, intestinal gas and intestinal worms.

\section{Red sandel}

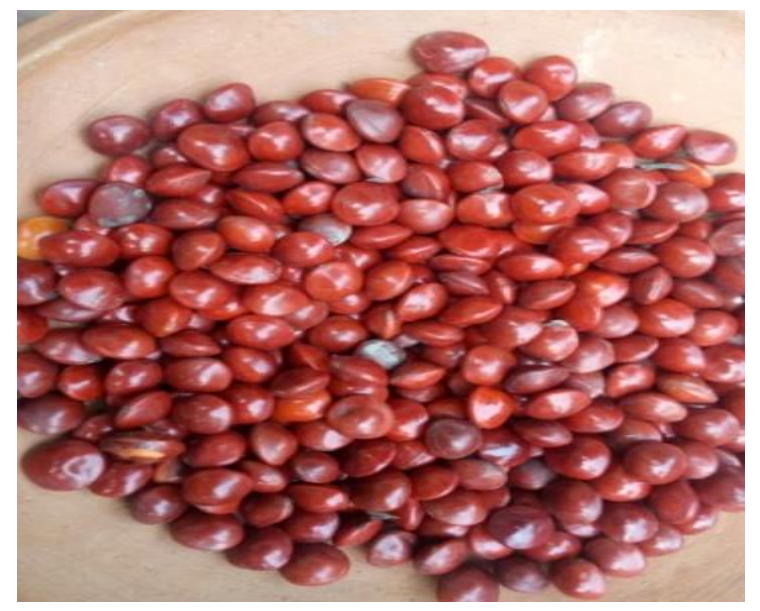

Figure 6: Pterocarpus santalinus Linn

English name: Red sandel

Scientific name: Pterocarpus santalinus Linn

Unani Name: Sandal sukh

Family: Fabaceae 


\section{Chemical Composition}

Fresh shoots yieldy gulcoside, coloring matter and marsupium.

Uses

Anti-inflammatory, antihelmintic, tonic, hemorrhage, dysentery, aphrodisiac, anti-hyperglycemic, anti-pyretic

\section{Tomato}

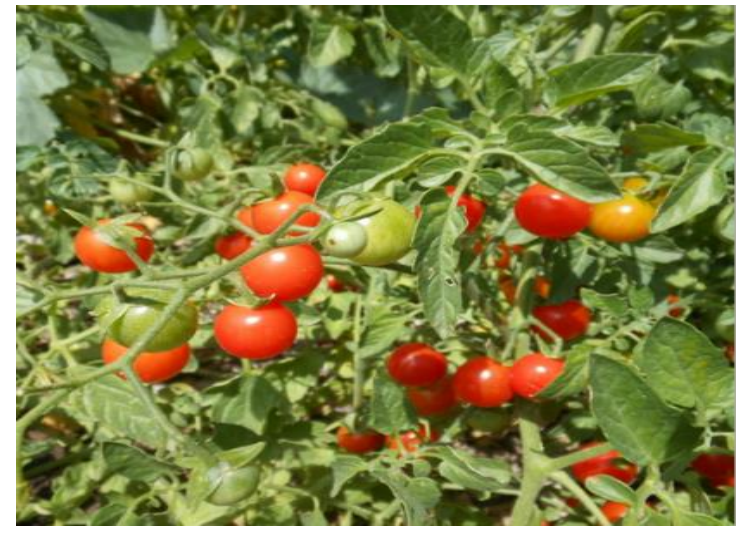

Figure 7: Solanum lycopersicum

English name: Tomato

Scientific name: Solanum lycopersicum

Family: Solanaceae

\section{Chemical Composition}

lycopene, citric acid, ethylene, tomatine, anthocyanin, cis-3-hexenal, 2-isobutylthia, solanine, naringenin, tomato cultivars (dorothy, boludo, thomas, dominique, dunkan).

\section{Uses}

Skin cancer, cervical cancer, colorectal cancer, stomach cancer, lung cancer, ovarian cancer, pancreatic cancer, prostate cancer, cardiovascular diseases, high blood pressure, cataracts, asthma, arthritis, common cold, chills, digestive disorder, urinary disorder, obesity, respiratory disorder.

\section{Wild Turmeric}

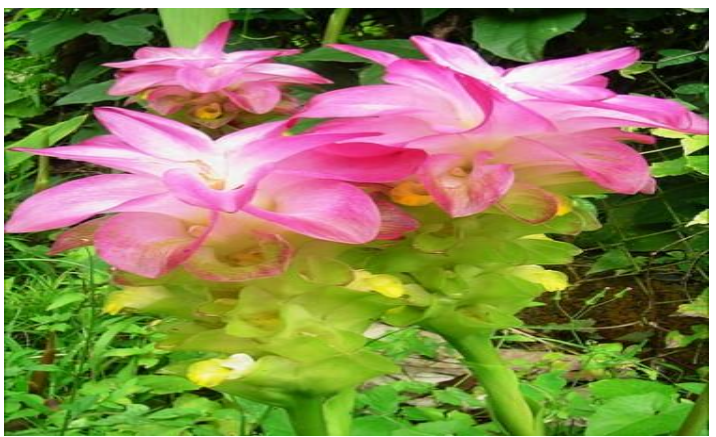

Figure 8: Curcuma aromatica Salisb 
English name: Wild turmeric

\section{Scientific name: Curcuma aromatica Salisb}

Unani Name: Darohoridra

Family: Zingiberaceae

\section{Chemical Composition}

Curdione, neocurdinone, curcumol, tetramethylpyrazine and rhizomes yield $6.1 \%$ essential oil, colouging matter and curcumin.

\section{Uses}

Leprosy, acne, scars, pigmentation, cellulite, inflammatory condition of skin, digestion, bleeding and dissolving clots, jaundice, internal hemorrhage, painful menstruation, shock, chest pain, angina, cancer.

\section{Vitex/Chaste Tree}

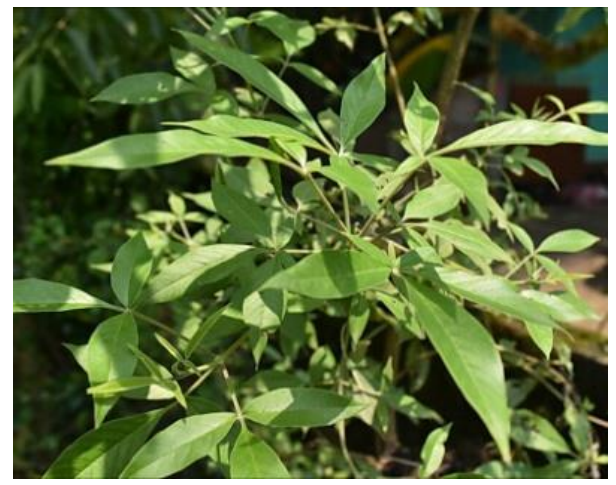

Figure 9: Vitex negundo Linn

English name: Vitex, Chaste Tree

Scientific name: Vitex negundo Linn.

Family: Lamiales

\section{Chemical Composition}

Alkaloids' viz. nishindineetc, Essential oil, Sterols, Terpenoid constituents. The principal constituents of the leaf juice are casticin, isoorientin, chrysophenol D, luteolin, p-hydroxybenzoic acid and D-fructose. The main constituents of the oil are sabinene, linalool, terpinen-4-ol, $\beta$-caryophyllene, $\alpha$-guaiene and globulol constituting $61.8 \%$ of the oil.

\section{Uses}

The leaf, seed and the root to treat excessive vaginal discharge, edema, skin diseases, helminthiasis, fever the menstrual cycle, fibrocystic breast disease. It has antiseptic, anti-inflammatory and antipyretic. 


\section{Senna alexandrian/Bombay Senna}

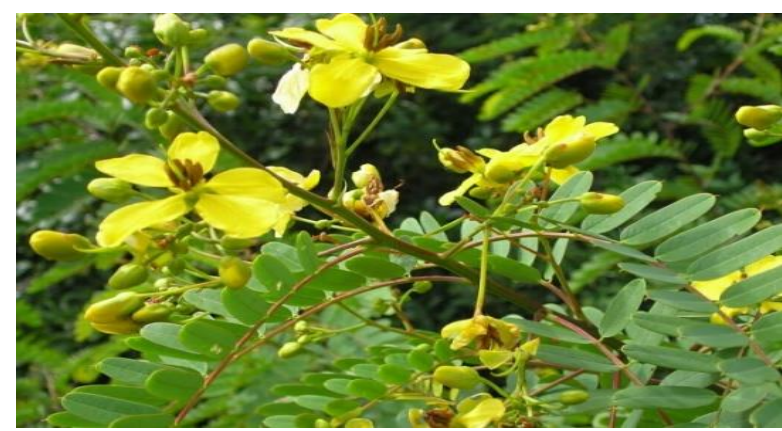

Figure 10: Cassia angustifolia

English name: Senna alexandrian /Bombay senna

Scientific name: Cassia angustifolia

Unani Name: Senna

Family: Legumionsae

\section{Chemical Composition}

Senna contains santhraquyinone glycosides, sennosides. there are small amount of aloeemodinj, mucilage, flavonoid.

Uses: Constipation a wound dressing and for the treatment of Gonorrhea, skin diseases, dyspepsia, fever and hemorrhoids.

\section{Chebulic myrobalan}

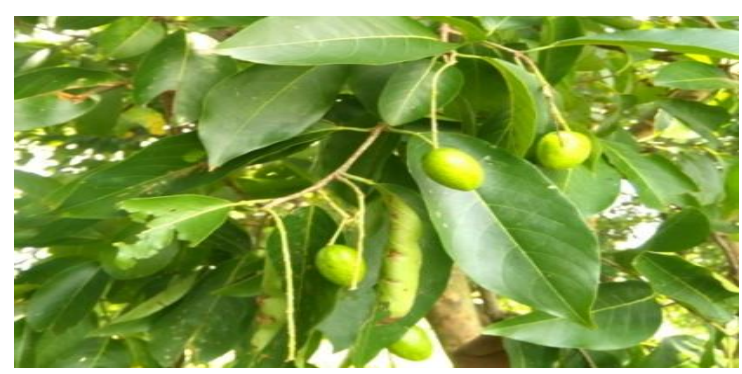

Figure 11: Terminalia Chebula

English name: Chebulic myrobalan

Scientific name: Terminalia Chebula

Unani Name: Holila

Family: Combretacea

\section{Chemical Composition}

Tannins, steroidal tritepenoids, flavonoid, glycosides, resins, proteins, amino acids, chebulicnic acid, chebulin, chebulic acid, luteoic acid. 


\section{Uses}

Fruits indigestion, constipation, jaundice, pills, painful menstruation, general tonic. eye discharge. Fruit is purgative, astringent, antiseptic, fever, cough, asthma, flatulence, colic, rheumatism, urinary diseases and skin diseases.

\section{Compound Drug}

Sharbat and Qurs Hazmin (Syrup \& Tablet Carmina), Sharbat Musaffi (Syrup Safi), Chyabon Prash, Majoon Ushba, Etrifal Ustukudush, Etrifal Shahtara.

\section{Silver Cocks Comb}

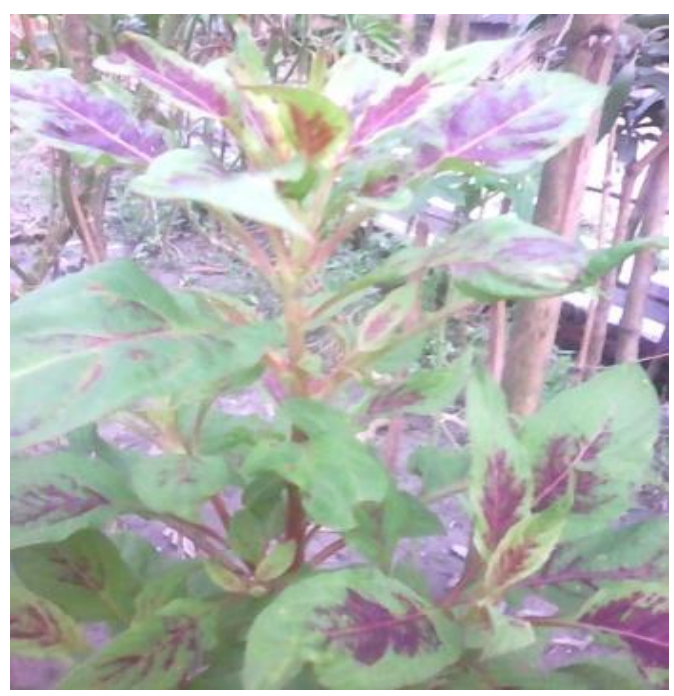

Figure 12: Celosta argentea

English name: Silver cocks comb

Scientific name: Celosta argentea

Family: Amaranthacae

\section{Chemical Composition}

It contains cochliophilin, isoflavone, cristatein, phenethylalcohol, kaempferol, quercetin, $\beta$-sitosteorol, octadecenoic acid, stigmasterol, saponins, celosin A-D, contains alkaloids, saponins, flavonoids, tannins and phenolic compounds.

\section{Uses}

Leprosy, skin hyper pigmentation, parkinson's disease and neuro-degenerative disorders like alzheimer's disease. Atherosclerosis, diarrhea, dysentery, abscess, cancer, pain and urinary tract infections. 


\section{Mackerel mint, Spearmint}

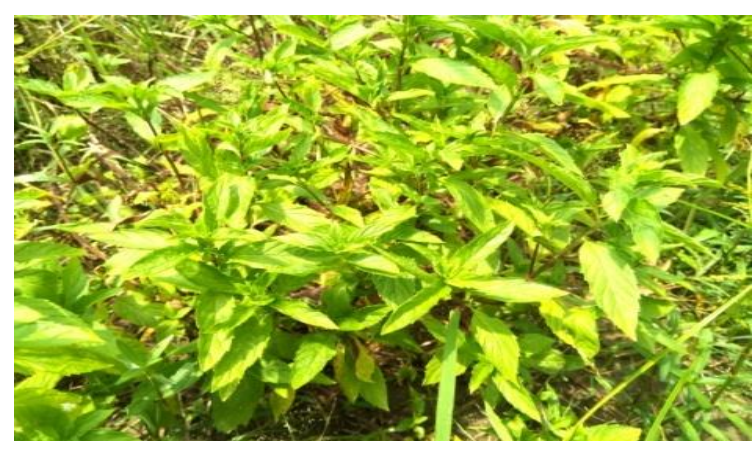

Figure 13: Mentha arvensis

English name: Mackerel mint, Spearmint

Scientific name: Mentha arvensis

Unani Name: Nana

Family: Lamiaceae

\section{Chemical Composition}

Leaves contain essential oil; the plant is rich in protein, amino acids and minerals. The oil characteristics similar to those of peppermint oil.

\section{Mode of Action}

Essential oil enhances appetite and facilitates digestion by promoting salivation, stimulating secretion of gastric fluids and reducing gastric colic through carminative action.

Essential oil helps to increase gastric emptying and is mildly irritating to the gastric mucosa so that peristalsis is increased, there by relieving cramping and expelling gas.

\section{Uses}

Herb is considered to be carminative and antispasmodic. Leaves are used in fever, bronchitis and are also given to stop vomiting and to treat Jaundice.

\section{Black Night Shade}
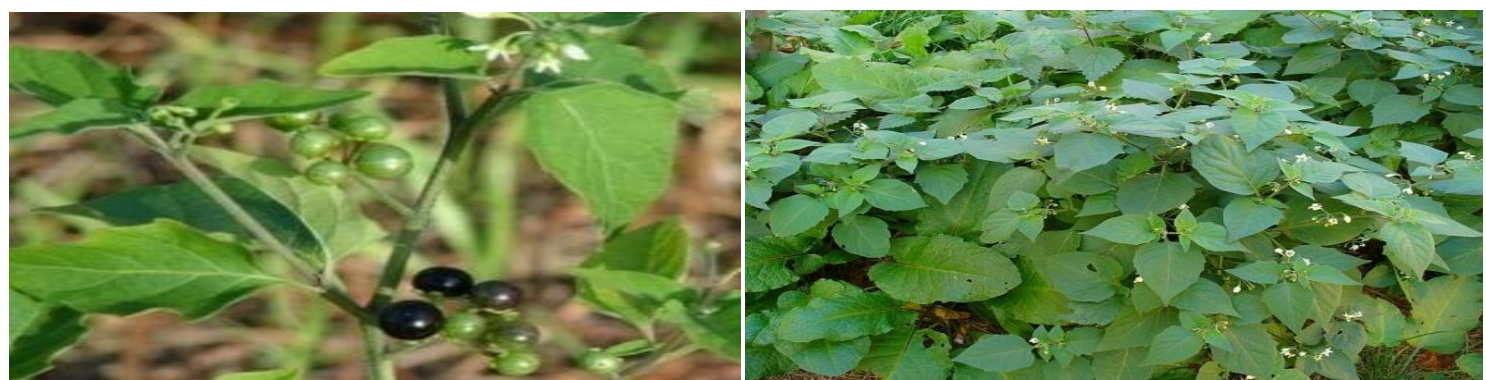

Figure 14: Solanum ingrum

English name: Black night shade 
Scientific name: Solanum ingrum

Unani Name: Makoya

Family: Solanaceae

\section{Chemical Composition}

Alkaloid-solanine, saponin, vitamins-riboflavin, nicrotic acid, vitamin c, beta carotene, sitosterol, steroidal glycoalkaloidssolamargine, solasonin and alpha and beta solanigrine, tygogenin.

\section{Mode of Action}

Solanine possesses hepato-protective activity. The hepato-protective effect is due to the stimulation of structural and function protein and phospholipids, as well as acceleration of the regeneration of hepatocytes.

Uses

Skin diseases, chronic enlargement of liver, diuretic, fever, eyes disease

\section{Rose}

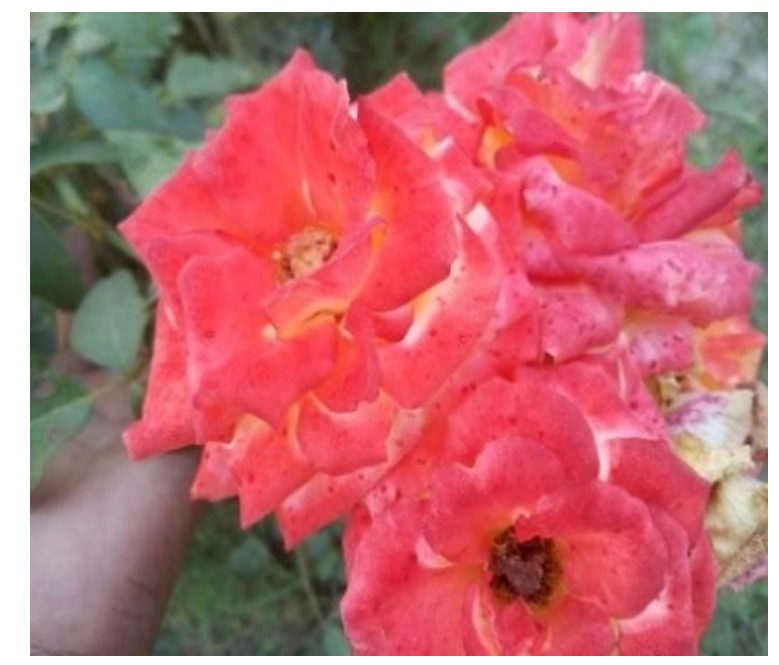

Figure 15: Rosa damascena

English name: Rose

Scientific name: Rosa damascena

Unani Name: Gula Shuk

Family: Rosaceae

\section{Chemical Composition}

Chromatographic profile of the rose oil, aliphatic hydrocarbons, monoterpene hydrocarbons, oxygen monoterpenes, sesquiterpene hydrocarbons, oxigensesquiterpenes, phenyl propanoids. citronellol, geraniol, nerol, phenyl ethyl alcohol, nonadecane, nonadecene, eicosane, heneicosane, tricosane, $\alpha$-guaiene, geranyl acetate and eugenol. phenyl ethyl alcohol $(71 \%)$ as the main citronellol, nonadecane and geraniol were the main components of rose essential oil triacosane (24.6\%), 1-nonadecene (18.6\%), n-tricosane (16.7\%) and geraniol (15.5\%), citronellol, geraniol, nonadecane and nerol. 
Chemical composition of rose oils: $\alpha$-Humulene, Camphene, $\delta$-Cadinene, Sabinene, n-Hexadecane, 8Heptadecene, n-Heptadecane, Phenylethylalcohl, Farnesyl alcohol, $\beta$-Linalool, n-Octadecane, cis-Rose oxide, Nonadecene, trans-Rose oxide, $n$-Nonadecane, Terpinene-4-ol, n-Eicosane, $\alpha$-Terpineol, Heneicosene, $\beta$-Citronellol, n-Heneicosane, cisGeraniol, n-Docosane, trans-Geraniol, (Z)-9-Tricosene, Citronellyl acetate, n-Tricosane, Geranyl acetate, n-Tetracosane, Eugenol, n-Tricosanol-1, $\beta$-Elemene, n-Pentacosane, Methyleugenol 1n-Heneicosane, $\beta$-Caryophyllene.

Uses

The antimicrobial, antioxidant, analgesic, anti-inflammatory, anti-diabetic and anti-depressant. Anti-depressant, antiseptic, antispasmodic, antiviral, aphrodisiac, astringent, hepatic, laxative, stomachic, and uterine substance. Traditionally used for treatment of abdominal and chest pains, strengthening the heart, menstrual bleeding, digestive problems and constipation, obstructed and irregular menses. It also eases cramps, nausea, and fatigue while reducing the pain associated with menstruation and post-menopausal syndrome. Bacterial infections like those in the colon, stomach, intestines, and urinary tract, as well as improved digestion can reduce the chances of constipation, diarrhea, irritable bowel syndrome (IBS), and even serious conditions like colorectal cancer.

\section{Chiretta}

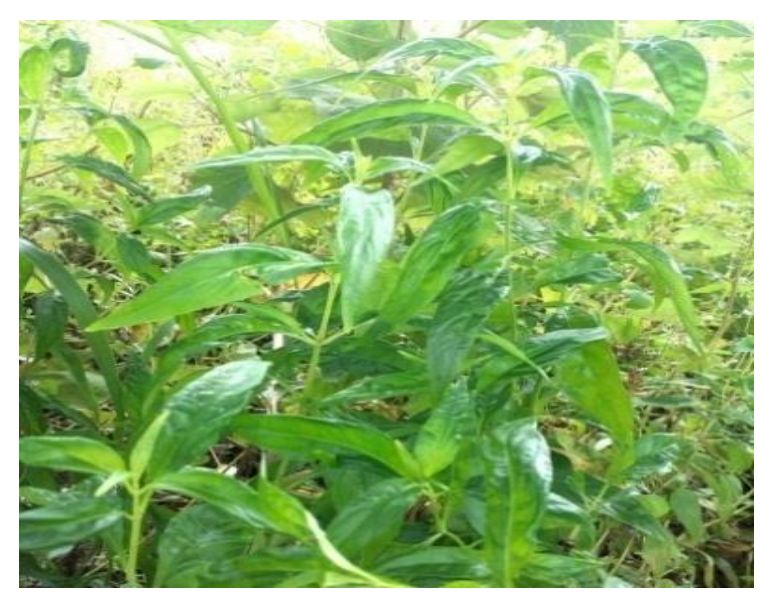

Figure 16: Androgrphis paniculata

English name: Creat, Chiretta

Scientific name: Androgrphis paniculata

Unani Name: Kalomegh

Family: Acanthaceae

\section{Chemical Composition}

Resin substance, kalomeghin, andrographilide, diterpenen glucosides, flavonoids, phenols. Leaves contain beta sitosterol glucoside, caffeic and chlorogenic acids.

\section{Uses}

Hepato-procreative, laxative, tonic and antiemetic, constipation, colic, dysentery and dyspepsia, in spleen complaints and debility, skin diseases. 


\section{Henna}

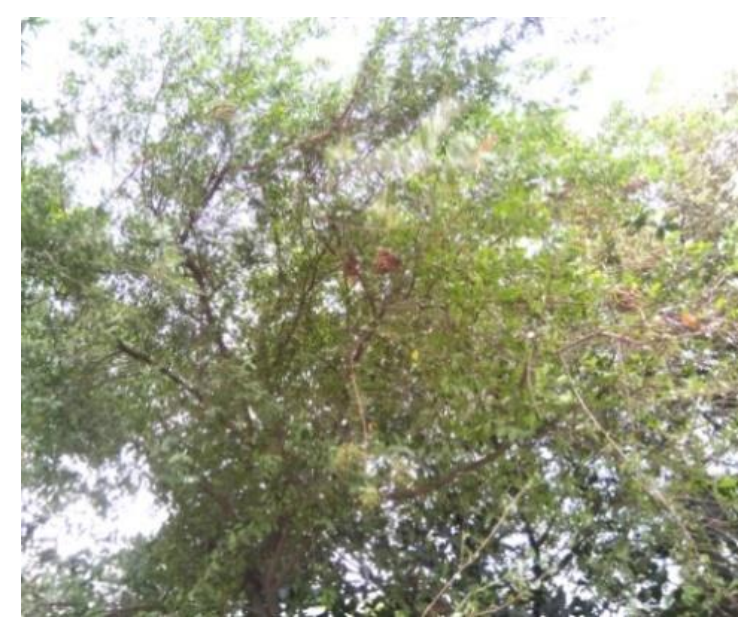

Figure 17: Lawsonia inermis Linn

English name: Henna, Samphire

Scientific name: Lawsonia inermis Linn

Family: Lythroideae

\section{Chemical Composition}

Essential oil, glycoside, coloring matter viz, 2-hydrox yalphnapthoquione, other constituents viz, hennotannic acid and fatty alcohols, leaves also vontains: hennotannic acid, garllic acid, mncilage, saponin, traces of alkaloids.

\section{Uses}

Eczema, scabies, fungal infections, and wounds, hair dyes, and hair care products; and as a dye for nails, hands, and clothing.

\section{Black Caraway}

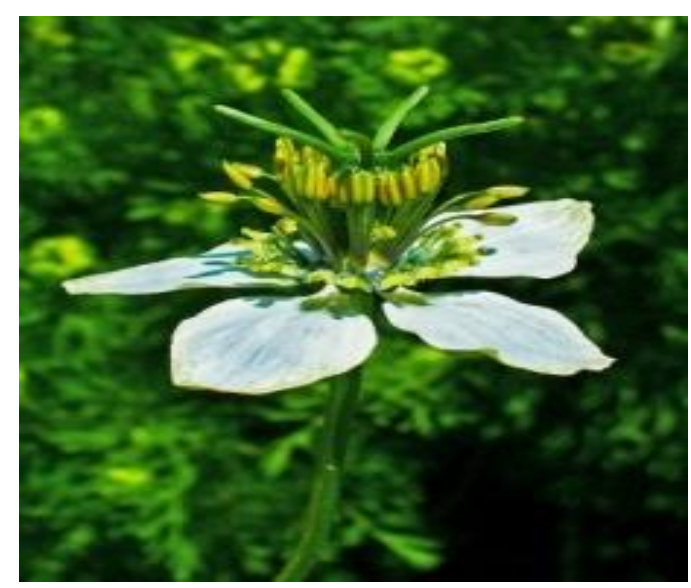




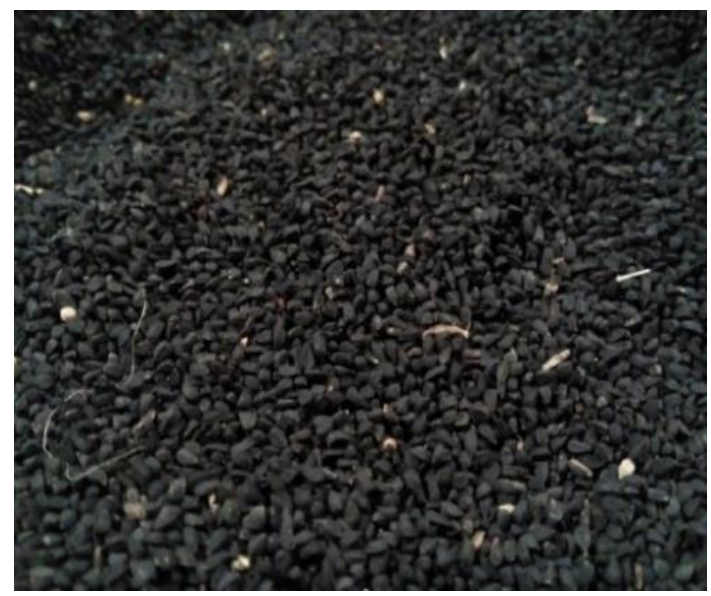

Figure 18: Nigella sativa Linn

Local name: Kalozira

Scientific name: Nigella sativa Linn

English name: Black caraway

Unani Name: Nigella sativa Linn

Family: Ranunculaceae

\section{Chemical Composition}

N. sativa oil contains linoleic acid, oleic acid, palmitic acid, and trans-anethole. Aromatics include thymoquinone, dihydrothymoquinone, pcymene, beta pinene, and trans-anethole. Seed also contain thymoquinone.

\section{Uses}

Asthma, diabetes, high blood pressure, breast pain, high fever, allergic rhinitis, itchy and inflamed skin, eczema, cancer treatment, dry nose, indigestion, epilepsy, stomach ulcer, hepatitis c, high cholesterol, leukemia, obesity, swollen tonsils, birth control, boosting the immune system, bronchitis, cancer prevention, congestion, cough, convention, diarrhea, headache, increases breast milk flow, menstrual disorder.

\section{Water Lily}

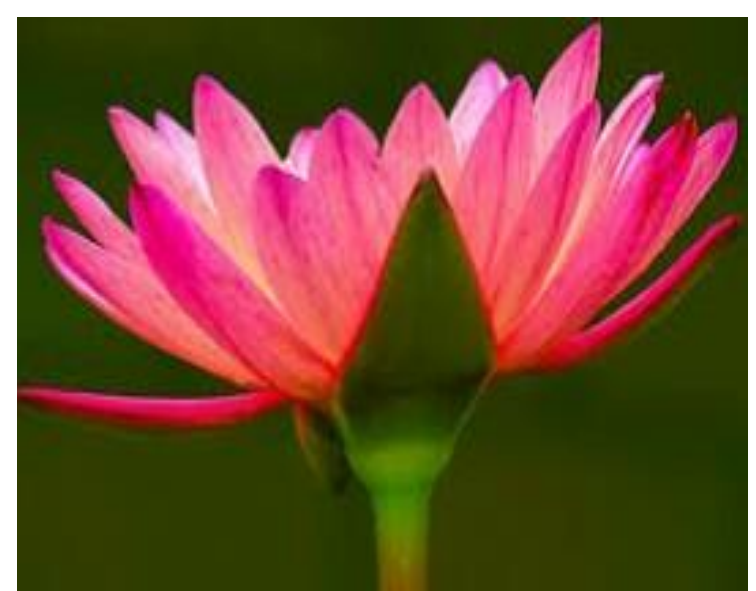

Figure 19: Nymphaea nouchali 
English name: Water Lily

Scientific name: Nymphaea nouchali

Unani Name: Nelufoor

Family: Nymphaeaceae

Chemical Composition: Hydrogen fluoride, which has 1 hydrogen atom in ratio to every 1 fluorine atoms. Sterols, alkaloids, saponins, tannins, flavonoids, nymphayol, protein, pentose, mucilage, and tannins are reported in the seeds. astragalin, corilagin, gallic acid, gallic acid methyl ester, isokaempferide, kaempferol, quercetin-3-methyl ether, quercetin, 2, 3, 4, 6-tetra-o-galloyl dextroglucose, and 3-o-methylquercetin-3'-o-beta dextroxylopyranoside have been identified in the flowers.

Uses: Diabetes, inflammation, liver disorders, urinary disorders, menorrhagia, menstruation problem, as an aphrodisiac, skin infection and as a bitter tonic.

\section{Shameplant}
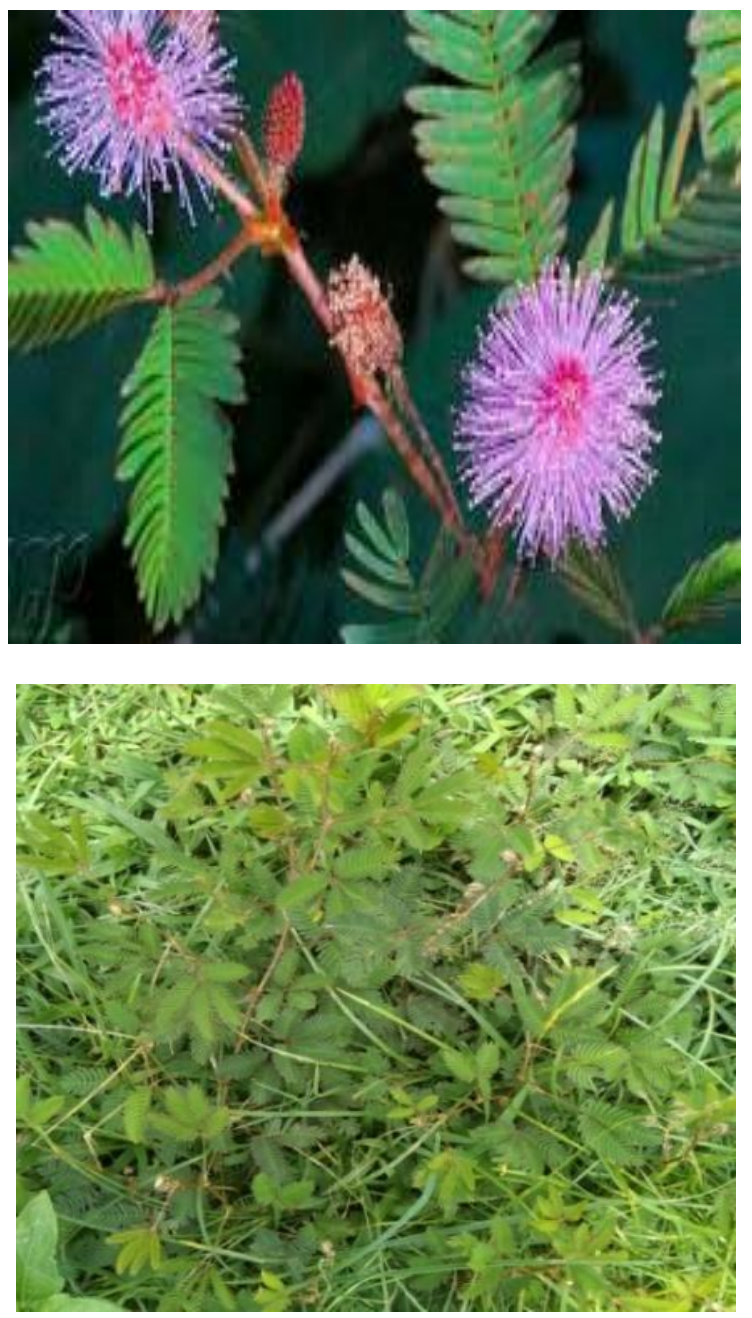

Figure 20: Mimosa pudica 
English name: Shameplant

Scientific name: Mimosa pudica

Unani Name: Lazwanti

Family: Leguminosae/ Fabaceae

\section{Chemical Composition}

Alkaloid mimosine, Alkaloid, Flavonoid C-glycosides, Sterols, Terenoids, Tannins, Fatty acids, adrenaline, D-glucuronic, acid, D-xyose, Methylsulfinic acid, Pyruvic acid, Lactic acid, Ethanesulfinic acid, 2-mercaptoaniline, S-propyl propane, 1thiosulfinate, Thioformaldehyde.

\section{Uses}

Anticancer, skin diseases, anxiety, depression and stress.

\section{Interactions}

Use anticancer, anti-inflammatory, antidepressant, and antibacterial.

\section{Water Pepper}

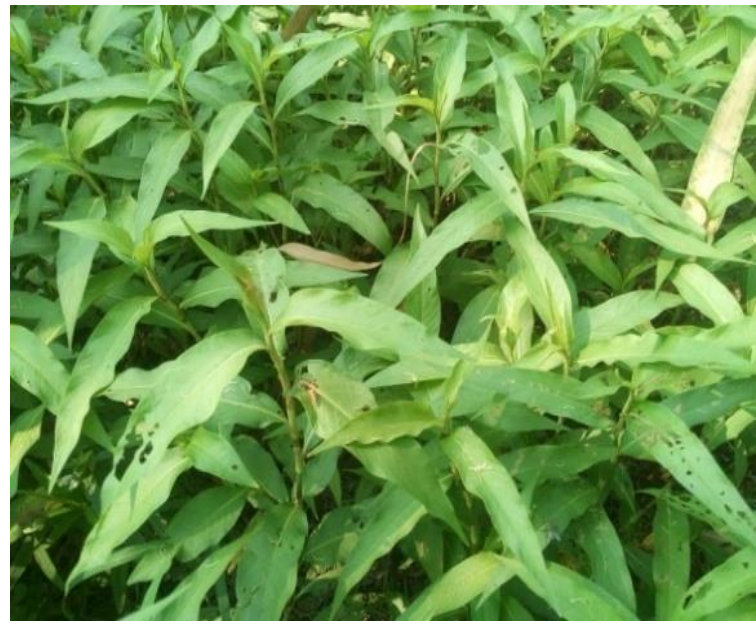

Figure 21: Persicaria hydropiper

English name: Water pepper

Scientific name: Persicaria hydropiper

Family: Polygonaceae

\section{Chemical Composition}

The plant contains an essential oil (0.5\%) which consists of monoterpenoids and sesquiterpenoids: $\alpha$-pinene, $\beta$-pinene, 1,4 cineol, fenchone, $\alpha$-humulene, $\beta$-caryophyllene, trans- $\beta$-bergamotene. Carboxylic acids (cinnamic, valeric and caproic acid) and their esters were present in traces. The composition depends strongly on genetic factors. 


\section{Uses}

The leaves are anti-inflammatory, diarrhea, dyspepsia, itching skin, excessive menstrual bleeding and hemorrhoids, astringent, carminative, diuretic, stomachic. The seed is carminative, diuretic and stimulant. The root is bitter, stimulant and tonic. A homeopathic remedy is made from the leaves. It is used in the treatment of piles, menstrual pains and other menstrual complaints

\section{Belerica Myrobalan}

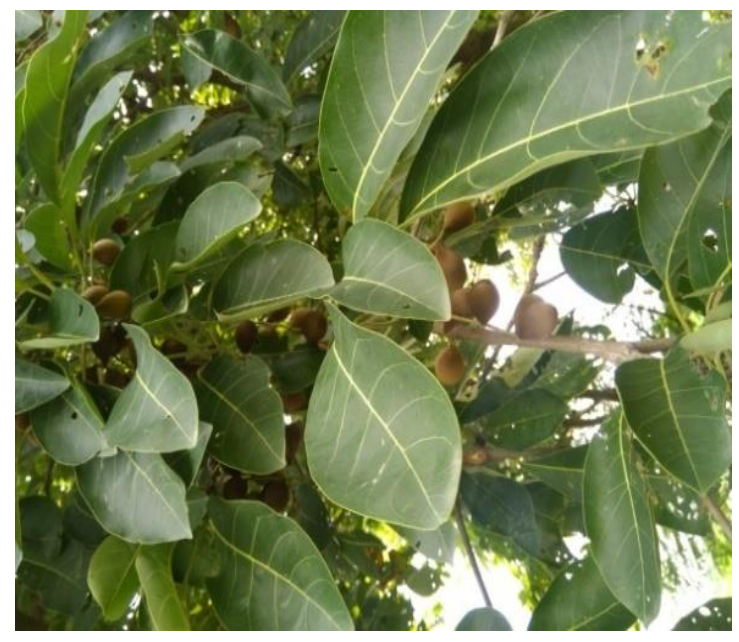

Figure 22: Terminalia bellarica

English name: Belerica Myrobalan

Local name: Bohera

Scientific name: Terminalia bellarica

Unani Name: Balila

Family: Combrtacea

\section{Chemical Composition}

Fruits: chebulagic acid, ellagic acid and ethyl ester, fructose, galactose, glucose and its galloyl derivative, mannitol and rhamnose and beta-sit sterol. bark: chebulagic acid and ellagic acid, seed-coat, Gallic acid.

\section{Medicinal Properties of Fruit}

Anti-diarrheal, astringent, antipyretic, anti-leprotic.

Uses

Useful in leprosy, cough, bronchitis, allergic cough, insomnia, edema, dyspepsia, eye disease, dropsy, piles and diarrhea. 


\section{Common Fig}

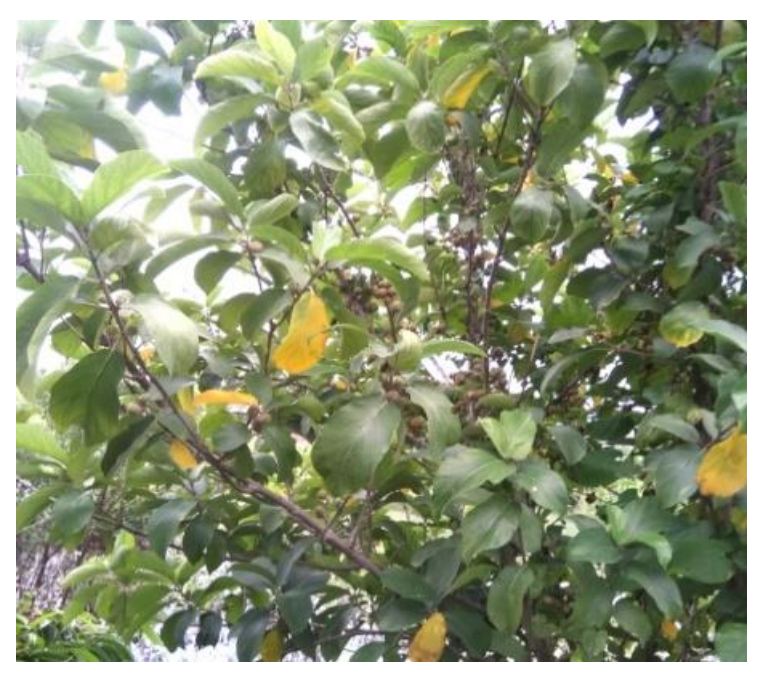

Figure 23: Ficus carica

English name: Common fig

Scientific name: Ficus carica

Family: Moraceae

\section{Chemical Composition}

Total phenol, flavonoid and anthocyanin, 2'-azinobis-(3-ethylbenzothiazoline-6-sulfonic acid) (ABTS) and 2, 2-diphenyl1-picrylhydrazyl (DPPH) radicals, acetylcholinesterase (AChE) and butyrylcholinesterase (BChE) Phenolic compounds, phytosterols, organic acids, anthocyanin composition, triterpenoids, coumarins, and volatile compounds such as hydrocarbons, aliphatic alcohols, Most species of F. carica contain phenol compounds, organic acids, and volatile compounds. Phenolic acids such as 3-O- and 5-O-caffeoylquinic acids, ferulic acid, quercetin-3-O-glucoside, quercetin-3O-rutinoside, psoralen, bergapten, and organic acids (oxalic, citric, malic, quinic, shikimic, and fumaric acids) have been isolated from the water extract of the leaves of F. carica. Four triterpenoids, bauerenol, lupeol acetate, methyl maslinate, and oleanolicacid,have been isolated from the leaves of F. carica and showed irritant potential on mice ears.

Gallic acid, chlorogenic acid, syringic acid, (+)-catechin, (-)-epicatechin and rutin. anthocyanins, with cyanidin3-O-rutinoside. 5-(hydroxymethyl)-2-Furancarboxaldehyde, 2,3-dihydro-3, 5-dihydroxy-6-methyl-4H-pyran-4-one, and 1, 3-dihydroxy-2-propanone. .

\section{Uses}

Metabolic, cardiovascular, respiratory, antispasmodic, and anti-inflammatory remedy. Gastro-intestinal, respiratory, inflammatory and cardiovascular disorders, vitamins, carbohydrates and dietary fiber because it is fat, cholesterol free and contain high number of amino acids, remove warts. 


\section{Lemon}

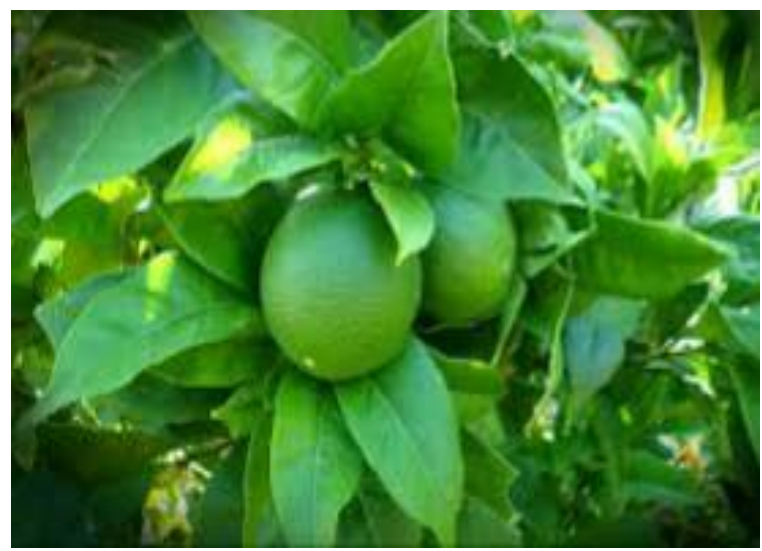

Figure 24: Citrus limon

\section{English name: Lemon}

Scientific name: Citrus limon

\section{Unani Name:}

Family: Rutaceae

\section{Chemical Composition}

Crude protein, phosphorus, calcium, copper, manganese, iron, zinc, sodium, potassium and some chemical parameters in feedstuffs. Sodium (Na), Potassium (K), Calcium (Ca), Copper (Cu), Iron (Fe), Magnesium (Mg), Zinc (Zn), Phosphorus (P), LOD: Limit Of Detection LO, Protein, Fiber, Ash, Fat.

\section{Uses}

Vitamin C, scurvy, astringent, gingivitis, stomatitis, and inflammation of the tongue, common cold, allergies, high blood pressure, kidney diseases, pregnancy including nausea and vomiting, decreasing swelling, increasing urine.

\section{Indian Pennywort}

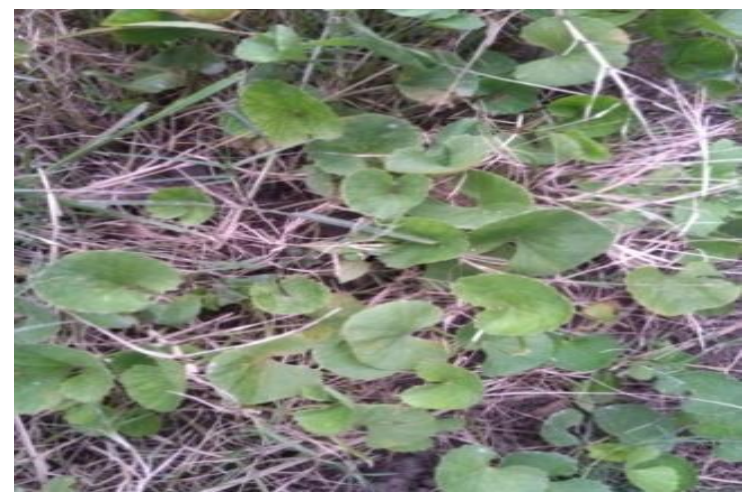

Figure 25: Centella asiatica

English name: Indian Pennywort 
Scientific name: Centella asiatica

Unani Name: Brahmi

Family: Apiaceae

\section{Chemical Composition}

Centella contains not less than $2 \%$ tritepene ester glycosides (asisticoside and madecassoide). Determination of asiaticoside and related tritepene ester glycosides triterpenoids, thankuniside, iso-thankunside, asiaticosides, madecassic acid and madecassoiside, thankunic, peptic and brahmic acids.

\section{Uses}

Is effective in enhance blood circulation in brain, skin diseases, peripheral vasodilator, leprosy, and cough.

\section{DISCUSSIONS}

In an attempt to provide clinically relevant data regarding both dermatologic disease and skin care needs in the elderly, Traditional healer aged Represents that Maximum 9 (42.8\%) studied population were attending in the study at Age 41-51 years and Minimum 04 (19.2\%) studied population were at age 20-30 years. Traditional healer Represents those Maximum $14(66.7 \%)$ Male patients were suffered Skin diseases and Minimum 7 (33.3\%) Female patients were suffered Skin diseases. Traditional healer Religion-Represents that Maximum 16 (76.2\%) Muslim patients and Minimum 1 (4.8\%) in Christian patients were suffering from Skin diseases. Traditional healer Educational status Represents that maximum 7 $(33.3 \%)$ skin diseases patients attending in the study were passed JSC and minimum was $4(19.00 \%)$ in HSC and PEC 4 (19.00\%) patients were suffered Skin diseases. Traditional healer are used for medicinal is Nim/ Margo, turmeric, Barbados salin, garlic, onion, read sandal, tomato, wild turmeric, chaste tree, senna, chebula myrobalam, silver cocks comb, spearmint, black night shade, rose, creat, henna, black caraway, water lily, water pepper, billerica, myrobalan, common fig, lemon and other medicinal plants but most important and right medicinal plants including thesis. This study estimated the point prevalence of self-reported occupational skin disease in clinical roles at 20\%; this figure is comparable with previously reported international data. By comparison, the estimated point prevalence of self-reported occupational skin disease in non-clinical roles was $7 \%$ which is comparable with the background level of eczema in the Pirganj. The study confirmed previous observations which showed that moisturizers are used more often in staff reporting skin problems and that occupational skin disease was reported more commonly where there was a history of eczema, where redness was reported and where hands were washed >20 times per day. No difference was found in the proportions of soap and alcohol gel use between the symptom and non-symptom groups, as reported in previous studies. Accepted advice is that in general, hand washing should be the exception to be performed only when skin is soiled or visibly contaminated with pertinacious material.

It was also found that non-clinical staff reported significantly more use of soap relative to alcohol gel than clinical staff, most likely because there is less need for them to use alcohol gel which is predominantly used in clinical settings.

The method used in this study enabled the direct comparison between subjects from the same population. However, due to the nature of the study, the skin was not examined. Neither was it possible to record hours of work and data such as hobbies and personal circumstances (e.g. caring for young children). More work is required to explore if the 
observed soap and alcohol gel ratios recorded in this study are commonplace and whether the type of skin preparation used has any impact on the development of occupational skin disease in Pirganj, Rangpur, Bangladesh.

\section{CONCLUSION AND RECOMMENDA- TION}

This study has identified 25 medicinal plants used for skin disease Treatment by Traditional Healer in Pirganj Upazila, Rangpur. Generally fresh part of the plant used to preparation of medicine. When fresh plant part are not available dried parts also used in primary health care of people. During the survey it was that there must need to protect this knowledge forever. This study was conducted in a selected area of Pirganj, Rangpur, Bangladesh. This might not reflect the actual scenario of the whole country.

\section{LIMITATIONS OF THE STUDY}

- $\quad$ Time and resources were limited.

- $\quad$ Single centered study and small sample size.

- There are no found in our university for research article.

- Financial is major problem.

\section{DISCLAIMER}

The products used for this research are commonly and predominantly use products in our area of research and country. There is absolutely no conflict of interest between the authors and producers of the products because we do not intend to use these products as an avenue for any litigation but for the advancement of knowledge. Also, the research was not funded by the producing company rather it was funded by personal efforts of the authors.

\section{CONSENT}

As per international standard or university standard, respondents' written consent has been collected and preserved by the author's.

\section{ETHICAL APPROVAL}

It's not applicable.

\section{ACKNOWLEDGEMENT}

With the name of Almighty Allah, The most merciful and the most sympathy towards his creation a grateful loving and compassionate direction keeps everyone peaceful and happy always.

I would like to give thanks to Almighty Allah for making it possible for me to complete my Bachelor of Unani Medicine and Surgery (BUMS) degree successfully and also given me the opportunity to witness the end of a successful research.

I would like to express my gratitude to all those who contributed to the development and completion of this work. First, I would like Acknowledge my supervisor Md. Masum Billah, Lecturer Department of Ayurvedic Medicine, Hamdard University Bangladesh, for this valuable suggestion, guidance and continuous support during conducting this research 
work. I would like to thanks my honorable Teacher Md. Abdul Mannan, Assistant Professor and Consult Microbiologist, for motivation and execute Dissertation related activities.

I must extend my sincere appreciation and heartfelt thanks to all teachers and stuffs of HUB.

\section{COMPETING INTERESTS}

Author has declared that no competing interests exist.

\section{REFERENCES}

1. Shankar D, Majumdar B. Beyond the biodiversity convention: The challenges facing the biocultural heritage of India's medicinal plants. In: Medicinal plants for forest conservation and health care, (non-wood forest products services). Anand RA, Kishore VO, Rajkumar V. Journal of Pharm Res.1993;11:163.3; 1993;3(11); 2010;2585-2587.

2. Ramakrishnappa K. Impact of cultivation and gathering of medicinal plants on Biodiversity: Case studies from India. In: Biodiversity and the Ecosystem Approach in Agriculture, Forestry and Fisheries; 2000.

3. Masood E. Nature; 1997;385-570.

4. Alschuler L, Benjamin SA, Duke Ja. Herbal medicine - what works, what is safe. Patient Care 1997; 3:48-103.

5. Bensoussan A, Talley NJ, Hing M, Menzies R, Guo A, et al. Treatment of Irritable bowel syndrome with Chinese herbal medicine: A randomized controlled trial. JAMA. 1998;280:1585-1589.

6. Carter JA Dwale. An anesthetic from old England. BMJ. 1999; 319:1623-1626.

7. Schuppan D, Jia JD, Brinkhaus B, Hahn EG Herbal product for liver Diseases: A therapeutic challenge for the new millennium. Hepatology. 1999;30:1099-1104.

8. Policepatel SS, Manikrao VG, Ethnomedicinal plants used in the treatment of skin diseases in Hyderabad Karnataka region, Karnataka, India. Asian Pac J Trop Biomed. 2013;882-886.

9. Abbasi AM, Khan MA, Ahmad M, Zafar M, Jahan S, et al. Ethno pharmacological application of medicinal plants to cure skin diseases and in folk Cosmetics among the tribal communities of North-west Frontier Province, Pakistan. J Ethnopharmacol. 2010;128:322-335.

10. Suresh M, Ayyanar M, Amalraj L, Mehalingam P. Ethnomedicinal plants used to treat skin diseases in Pothigai hills of Western Ghats, Tirunelveli district, Tamil Nadu, India. J Biosci. 2012;3:112-121.

11. Saikia AP, Ryakala VK, Sharma P, Goswami P, Bora U, Ethnobotany of medicinal plants used by Assamese people for various skin ailments and cosmetics. J Ethnopharmacol. 2006;106:149-157.

12. Kumar P, Vidyasagar GM, Traditional knowledge on medicinal plants used for the treatment of skin diseases in Bidar district, Karnataka. Indian Journal of Traditional Knowledge. 2008;7:273- 276.

13. WHO survey. In medicinal plants (Eds. Haq. I.), (Hamdard Foundation Press, Karachi); 1993.

14. Sirkar NN. Indian Materia Medica (Popular Prakshan Pvt. Ltd, Bombay); 1976.

15. Available:www.ncbi.nlm.nih.gov/pmc/articles/PMC3931201/\#!po=73.979675 